\title{
Optimization The Performance of a Synchronization Controller for a 3-Phase Photovoltaic Grid-Connected System
}

\author{
Bennis Ghita ${ }^{1}$, Karim Mohammed ${ }^{2}$, Lagrioui Ahmed ${ }^{3}$ \\ ${ }^{1,2}$ LISTA Laboratory, Faculty of Sciences Dhar El Mahraz, Sidi Mohammed Ben Abdellah University Fès, Morocco \\ ${ }^{3}$ Department of Electrical Engineering And Computer Engineering, National School of Arts and Métiers, University \\ Moulay Ismail Meknes - Morocco
}

\begin{tabular}{l} 
Article Info \\
\hline Article history: \\
Received Jan 11, 2018 \\
Revised Apr 10, 2018 \\
Accepted Apr 24, 2018 \\
\hline
\end{tabular}

\section{Keyword:}

Inverter

MPPT

PLL

PSD

PV Array

\begin{abstract}
In a distributed generation system, divers renewable agents are connected to the low voltage 3 phase utility grid by an inverter which is used as power condition and must assurance the higher efficiency of the renewable agent. To achieve this level of efficiency, a unitary power factor between the utility grid voltages and the inverter currents is necessary, and a synchronization algorithm is required for the perfect synchronization between the 3-phase utility grid and the renewable agent. The aim of this paper is to present the optimization of the performance of a Synchronization controller for a 3phase photovoltaic grid-connected system, assessing its accuracy under different conditions and studying their drawbacks and advantages. A grid connected photovoltaic system with a nominal power of $5 \mathrm{~kW}$ is used so as to assess the behavior of the synchronization algorithm when the 3 phase utility grid is affected by some disturbances such as voltage unbalances.
\end{abstract}

Copyright (C) 2018 Institute of Advanced Engineering and Science. All rights reserved.

\section{Corresponding Author:}

Bennis Ghita,

LISTA Laboratory

Sidi Mohammed Ben Abdellah University Fès

Faculty of Sciences Dhar El Mahraz, Morocco

Email: ghita.bennis@usmba.ac.ma

\section{INTRODUCTION}

Solar energy has become the most popular renewable energy source where in energy is extracted directly from sun employing photovoltaic modules [1-4]. The power electronics converters, variable nonlinear loads and voltage regulators inject harmonics to the grid and are accountable for serious power quality problems [5]. Indeed, there are a number of outstanding problems mainly related to the power quality, such as reactive power compensation, power factor, harmonics and voltage regulation in a photovoltaic system connected to grid [6]. The global performance of the total system gets affected and it becomes a serious concern for the final users. Any integration of renewable energy sources to the grid has to meet standard power quality requirements. The power quality expected from distributed generations has been the subject of discussion and standardization.

In a Photovoltaic system, the signal quality is of particularly preoccupied due to high proportion of nonlinear and single-phase loads. moreover, switching of a single-phase load can depict a large transient leading to sag and swell of voltage signal. generally, the grid connected Photovoltaic system fails to control harmonic currents and the reactive power drawn by the nonlinear load. mostly passive filters are used to control the harmonics currents generated. But due to divers disadvantages like series/parallel resonance, these filters have been changed and also these filters are not suitable for certain loads [7]. Active power filter is a better choice which ameliorates harmonic compensation features of the passive filter.

In this works new control algorithms have been designed focusing on increasing the performance of the connection of primary renewable energy agents to the low voltage 3 phase utility grid. It is essential an 
appropriated control of the power factor of the inverter grid connection to get the maximum efficiency in the photovoltaic agent, and the synchronization algorithm will be one of the aim modules in detecting the phase angle of the 3 phase utility grid voltages with optimal dynamic response. the Synchronous Reference Frame Phase Locked Loop (dqPLL method) is the classical synchronization algorithm, in view of it is easy to implement, but it is also very sensible to grid voltage unbalances leading to errors when the frequency and phase are detected. For this, a big amount of studies has been carried out in this area in order to discover a solution to this fact, as may be found in [10-14], the most of them showing a perspective of how to solve this issue when the detection of the frequency is conducted.

\section{GRID CONNECTED PHOTOVOLTAIC SYSTEM}

this paper focuses on for Photovoltaic grid-connected systems is to control the power flow between the primary renewable energy source and the utility grid [17], in addition to the power factor of the invertergrid connection with high power quality [18]. The power conditioner should guarantee the maximum efficiency by injecting the maximum available power at the Photovoltaic module, also by controlling the power factor of the inverter grid connection in a four quadrant operation, the last makes use of the instantaneous reactive power theory [19] for 3 phase systems which enable the control of the instantaneous active and reactive powers in decoupled $\mathrm{d}-\mathrm{q}$ axes [20]. The general 3 phase Photovoltaic grid connected system can be divided into two subsystems [18], the control and the power subsystems, whose block diagrams are depicted in Figure 1. In the present study, the power converter of the Photovoltaic system shown in Figure 1 works in inverter mode (3 phase Voltage Source Inverter (VSI)) for it delivers all the incoming power from the PV generator into the 3-phase utility grid, even though an opposite power flow is also possible (rectifier mode), being capable to feed local dc loads from the utility grid.

\section{POWER SUBSYSTEM}

The power subsystem is formed by the Photovoltaic modules, a converter controller by MPPT, and inverter and the LCL filter. ensuing, a brief description of each block is developed.

\subsection{Photovoltaic modules}

the Photovoltaic modules are the aim part of a PV system [21]. There are various kinds of PV module technologies with different levels of efficiencies [1]- [22]. The function of a Photovoltaic module is to supply the necessary power for the renewable grid connected system, and it will depend of the temperature and the available solar irradiance [23], signify while its size (arrange of parallel-series PV cells) will depend of the required power of the photovoltaic system [24].

\subsection{The converter controller by MPPT}

the boost converter is used not only to uplift the Photovoltaic array output voltage, but also to realize Perturb and Observe $(\mathrm{P} \& \mathrm{O})$ scheme in Maximum Power Point Tracking (MPPT). The boost converter connected to Photovoltaic array, forever works in a continuous current mode and the current ripple is reduced by using a large value of inductor. A low value of capacitor at output acts as filter.

\subsection{The inverter}

The work of the inverter, principally built with semi-conductor electronic devices [9] (IGBTs and diodes), is to convert the generated dc voltage into appropriate ac currents to be fed into the 3 phase low voltage utility grid [7,9]. Pulse width modulation (PMW) and space vector modulation (SVM) [25] techniques are utilized to control the gate signals of power switches according to the current references and averaged voltage. in Figure 1, the dc of the inverter can be described as follows:

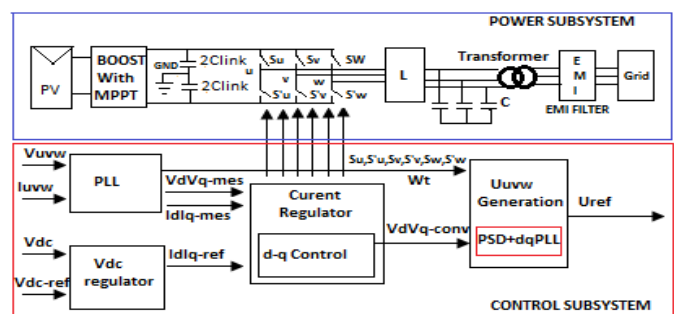

Figure 1. Block diagram of the power and control subsystems for the 3-phase grid-connected PV system. 


$$
\begin{gathered}
\text { ip }=\text { iclink }+ \text { icc } \\
\text { icc }=\text { Su.iu }+ \text { Sv.iv }+ \text { Sw.iw } \\
\text { iclink = cclink }(d V c c / s t) \\
\text { Ppv }=\text { ip Vp }
\end{gathered}
$$

where vp, ip are the voltage and the output current of the Photovoltaic generator, respectively, PPV is the available power for a specific irradiance, $\mathrm{Vcc}$ is the dc bus voltage, ic link is the current through the link capacitor Cclink, and icc is the current issued to the 3 phase VSI (which is a function of the line currents iu, iv, iw and the states of the power-poles $\mathrm{Su}, \mathrm{Sv}, \mathrm{Sw}(1$ : 'on', 0: 'off', Si-upper pole, S'I lower pole in the 3 phase VSI). Taking into account that the voltage in the capacitor is approximately the same that the voltage in the three-phase utility grid, the dynamic in the ac of the inverter expressed in a vector way is as follows:

$$
u-u_{A C}+L \frac{d i}{d t}=u_{R}+u_{L}
$$

Where $\mathrm{U}$ is inverter voltage, $\mathrm{i}$ : inverter line current, Uac: utility grid voltage space vectors, $\mathrm{L}$ : the line inductance, $\mathrm{R}$ : resistance.

Expressing the last vector equation with its $d$ and $q$ components in $d-q$ axes using the Park vector transformation $[18,26]$, the instantaneous active power $(\mathrm{p})$ and the instantaneous reactive power $(\mathrm{q})$ can be expressed as follows [17,25]:

$$
\begin{aligned}
& \mathrm{P}=\mathrm{UACd} \text { id }+ \text { UACq iq } \\
& \mathrm{q}=\text { UACd id }- \text { UACq iq }
\end{aligned}
$$

Where UACd, UACq, idand iqare the $\mathrm{d}-\mathrm{q}$ components of 3-phase voltages and currents, respectively, allowing a decoupled control of the instantaneous active and reactive powers if vector Uac is aligned with the $\mathrm{d}$ axis $(\mathrm{UACq}=0)$.

\subsection{LCL Filter}

In addition of guaranteeing a constant power delivery to the3-phase utility grid, renewable agents must fulfill the power quality regulations. The maximum total harmonic distortion (THD) for the 3-phase currents must be around 5\% [28] according to heteronormative [6,29], whereas the normative for the low order harmonic distortions is indeed more restrictive. An abstract of different standards about power quality for photovoltaic systems can be found in [30]. Ripples are produced in the output currents of the inverter due to the high frequency commutation of the IGBTs, meanwhile the low order harmonics are produced by nonlinear loads. The good solution for correcting the high frequency ripples is by utilizing an LC or an LCL filter in the ac side of the inverter [31].

\subsection{EMI filter}

In a grid-connected renewable agent, it is essential to take into account the harmonic pollution due to the Electromagnetic Interference (EMI). These EMIs are produced by the commutation of semiconductor electronic devices (IGBTs and diodes) [30] and an EMI filter is required to reduce it. There are various methodologies to design an appropriate EMI filter, some of them are founded on trial an error [30,31], and some novel methodologies are cited in several publications, including [33,34].

\section{CONTROL SUBSYSTEM} generation.

The control subsystem is formed by the PI regulators, PSD synchronization, and the and the Uuvw

\subsection{PI Regulators}

regulators The implemented control strategy utilizes a cascaded control: an outer voltage regulator and an inner current regulator. This control has been performed utilizing PI controllers [17]: the outer loop regulator compares the dc bus voltage in the link capacitor with the reference which arrives from the block Vdc regulator keeping a constant dc voltage and making the power balance between the Photovoltaic system and the utility grid, whereas the inner control loop utilizes two controllers to regulate the $\mathrm{d}-\mathrm{q}$ components of the line currents permit the synchronization of the 3 phase inverter line currents with the 3 phase utility grid 
voltages. A block diagram of the continuous equivalent low signal model of the cascaded control for the 3 phase VSI used for Photovoltaic systems is depicted in Figure 2.

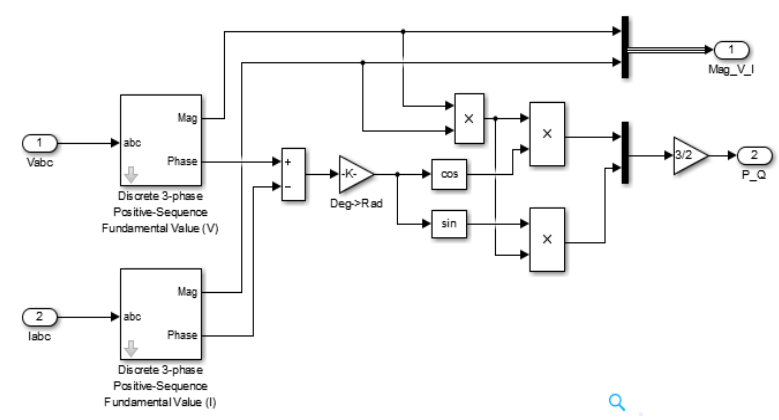

(a)

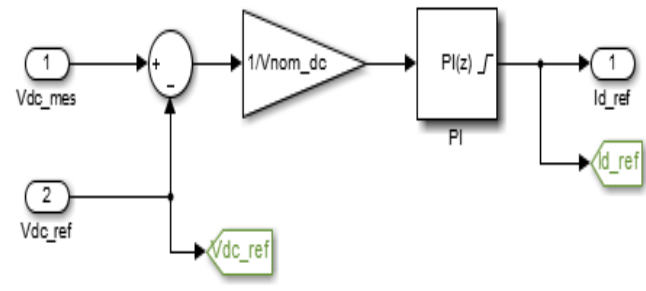

(b)

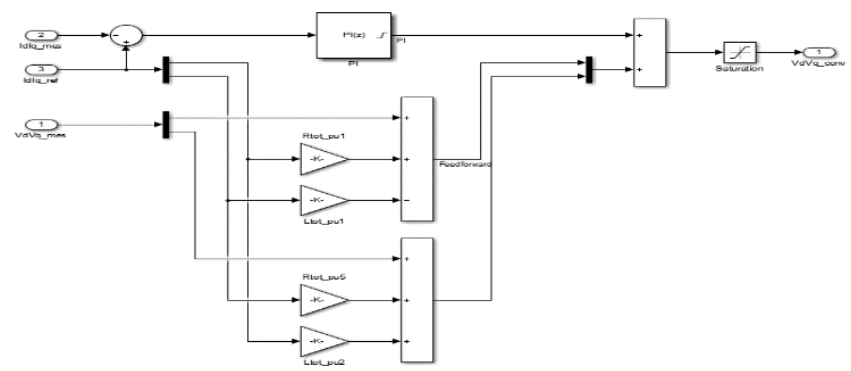

(c) bloc diagram of current regulator

Figure 2. (a,b,c,) bloc diagram of controller for 3-phase VSI for PV system

The synchronization algorithm for arriving a controllable power factor in the connection should detect the phase angle of the 3 phase utility grid voltages with optimal dynamic response and reliability in order to get the synchronization of the controlled 3 phase inverter currents and assure the proper behavior of the inverter control strategy. There are various studies which show different structures for synchronization algorithms [12], existence the Phase Locked Loop the classical one. A 3 phase Phase Locked Loop (PLL) structure is shown in Figure 3, which is made by the Clarke and Park transformations (also known as abc $\rightarrow$ $\mathrm{dq}$ transformation), the PI regulator as the loop filter, and an integrator as the voltage-controlled oscillator (VCO). This PLL structure is evenly known as Synchronous Reference Frame PLL or dqPLL: the input variables are the 3 phase utility grid voltages(ua,ub,uc), and the output variable is the phase angle (Oobs). The design of the Phase Locked Loop gain is a critical point within this process. The closed loop transfer function of the dqPLL is giving by:

$$
\mathrm{H}(\mathrm{s})=(\mathrm{KpS}+\mathrm{Ki}) /\left(\mathrm{S}^{2}+\mathrm{KpS}+\mathrm{Ki}\right)
$$

where $\mathrm{Kp}$ is the proportional gains employed PI regulator, Ki: integral gains of the employed PI regulator. Eq. (5) is a second order transfer function, similar to (6).

$$
\mathrm{G}(\mathrm{s})=\left(2 \xi \omega 0 \mathrm{~S}+\omega 0^{2}\right) /\left(\mathrm{S}^{2}+2 \xi \omega 0 \mathrm{~S}+\omega 0^{2}\right)
$$

where $\omega 0$ is the natural angular frequency, $\xi$ : is the damping factor. from equating (5) and (6):

$$
\begin{aligned}
& \mathrm{Kp}=9.2 / \mathrm{Ts} \\
& \omega 0=\mathrm{Kp} / 2 \xi \\
& \mathrm{Ki}=\omega 0^{2}
\end{aligned}
$$

In this work, the dqPLL gains are calculated so as to obtain $\mathrm{TS}=0.05 \mathrm{~ms}$ (one $50 \mathrm{~Hz}$ cycle) allowing a fast response of the algorithm when a variation of the nominal frequency occur, and a damping factor $\xi=$ 
0.871 is chosen. Equating (7) $-(9)$, the another variable can be computed: $\mathrm{Kp}=60, \omega 0=37.41 \mathrm{rad} / \mathrm{s}$ and $\mathrm{Ki}=$ 1400. The value give of $\omega 0$ guarantees a trade-off between the dynamic, the stability and harmonic rejection capability of the dqPLL algorithm.

The dqPLL method is very sensible to grid voltage unbalances [8], which also produces second order harmonics in $\mathrm{d}-\mathrm{q}$ synchronous reference frame due to the effect of the inverse sequence, in fact, the sensors to be utilized can introduce second order harmonics due to accuracy errors. moreover, the 3 phase low voltages of the utility grid could be contaminated with harmonics and assumed by variations of the fundamental frequency. A resolution to the problems caused by the unbalance 3 phase utility grid voltages is adding a PSD block, which is founded on the symmetrical components method [15]. it is possible to decompose the unbalanced 3 phase utility grid voltages in negative, positive and zero sequences, allowing a good performance of the PLL algorithm. In time domain, the instantaneous positive sequence component $\mathrm{V}+\mathrm{abc}$ of a voltage vector is given by [10]:

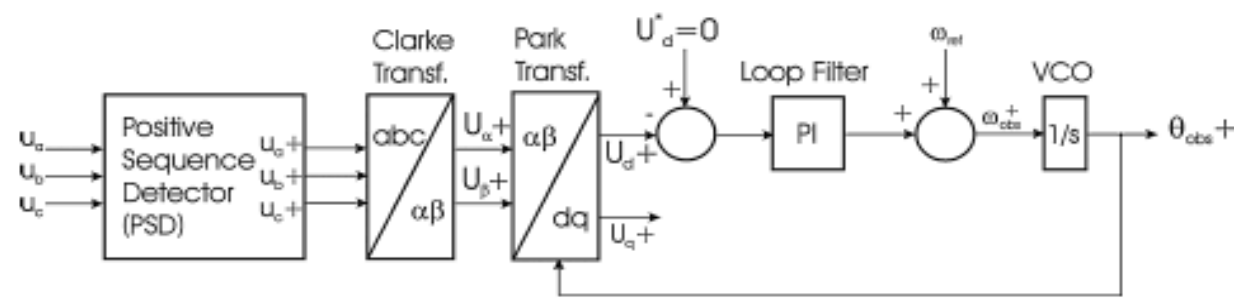

Figure 3. Block diagram of the PSD + dqPLL synchronization algorithm.

$$
\begin{aligned}
& \mathrm{Va}+(\mathrm{t})=0.5 \mathrm{Vc}(\mathrm{t})-((1 / 6)(\mathrm{Vb}(\mathrm{t})+\mathrm{Vc}(\mathrm{t}))-(1 / 2 \sqrt{3}) \operatorname{Sgg}(\mathrm{Vb}(\mathrm{t})-\mathrm{Vc}(\mathrm{t})) \\
& \mathrm{Vb}+(\mathrm{t})=-(\mathrm{Va}+(\mathrm{t})+\mathrm{Vc}+(\mathrm{t})) \\
& \mathrm{Vc}+(\mathrm{t})=0.5 \mathrm{Vb}(\mathrm{t})-((1 / 6)(\mathrm{Va}(\mathrm{t})+\mathrm{Vb}(\mathrm{t}))-(1 / 2 \sqrt{3}) \operatorname{Sgg}(\mathrm{Va}(\mathrm{t})-\mathrm{Vb}(\mathrm{t}))
\end{aligned}
$$

where S90 is a 90-degree phase-shift operator can be designed with the following transfer function:

$$
\operatorname{HS} 90(\mathrm{~S})=(1-(\mathrm{s} / \omega 0)) /(1+(\mathrm{s} / \omega 0))
$$

By adding the PSD block with Eqs. (10)- (12) to the dqPLL structure, a PSD + dqPLL synchronization algorithm able to extract the positive sequence of the 3-phase utility grid voltagesis obtained, and then, a reliable detection of the positive sequence of the frequency and phase will be achieved when voltage unbal-ances occur. A possible drawback of the PSD can be observed in Equation (13). The S90 phase-shift operator has been implemented using a non-adaptive nominal angular frequency $\omega 0$, making this filter sensibleto frequency variations of the utility grid voltages, which will lead to a small degradation.

\subsection{Vuvw Reference Generator}

The reference voltage signal for generating the pulses is generated in Vuvw reference generator diagram, which is shown in figure 4 below: 


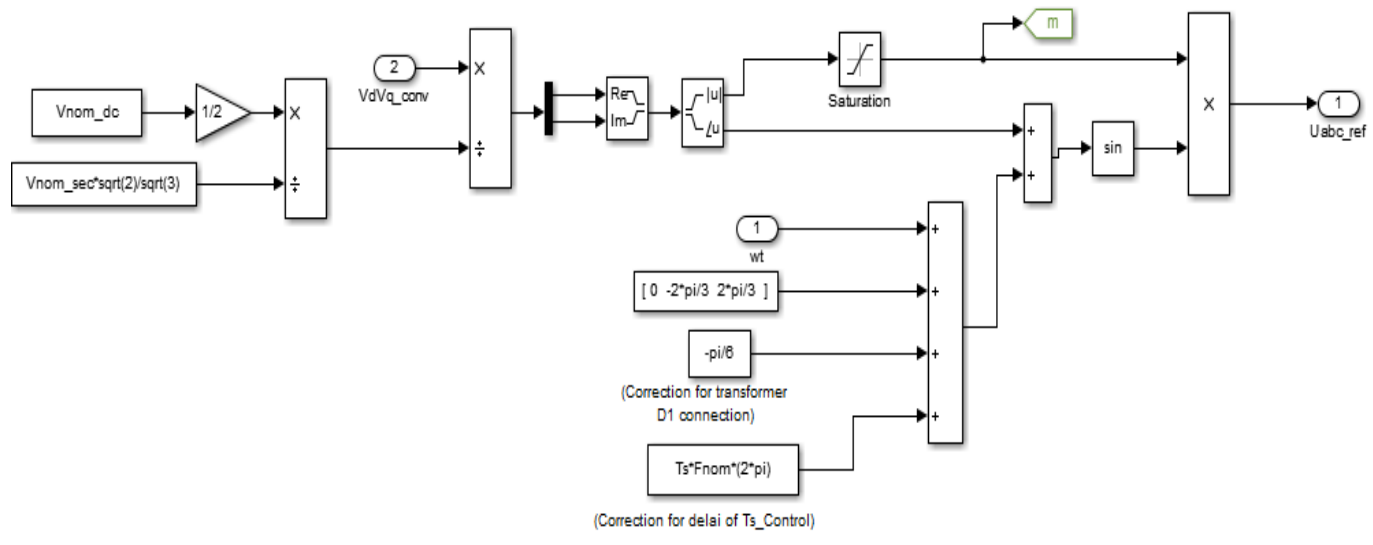

Figure 4. Vuvw reference generator diagram

\section{CASE OF STUDY}

A Photovoltaic grid connected system of $5 \mathrm{~kW}$ of nominal power at standard conditions (1000 $\mathrm{W} / \mathrm{m} 2$ and $25^{\circ} \mathrm{C}$ ) will be studied in order to evaluate the control algorithms performance.

A $5 \mathrm{~kW}$ Photovoltaic array is connected to a $25-\mathrm{kV}$ grid via a boost converter and a three phase three level Voltage Source Converter. MPPT is connected in the boost converter using the Perturb and Observe 'P\&O' technique.

The elaborate model includes the following components:

1. Photovoltaic array delivering a maximum of $5 \mathrm{~kW}$ at $1000 \mathrm{~W} / \mathrm{m}^{\wedge} 2$ sun irradiance.

2. $5 \mathrm{kHz}$ boost converter increasing voltage from Photovoltaic natural voltage $(273 \mathrm{~V} \mathrm{DC}$ at maximum power) to $500 \mathrm{~V}$ DC. Switching D is optimized by a MPPT controller that utilizing the 'P\&O' technique.

3. 1980-Hz 3 level 3 phase boost converter. The Voltage source converter converts the $500 \mathrm{~V}$ DC link voltage to $260 \mathrm{~V}$

$\mathrm{AC}$ and keeps unity power factor. The Voltage source converter control system utilizing two control loops: an external control loop which control DC link voltage to $+/-250 \mathrm{~V}$ and an internal control loop which regulates Iq and Id grid currents. Id current reference represent the output of the DC voltage external controller. Iq current reference is fixe to zero in order to maintain unity power factor. $\mathrm{Vd}$ and $\mathrm{Vq}$ voltage outputs of the current controller are transformed to three modulating signals Uuvw_ref used by the PWM Generator. The control system utilizes a sample time of 100 microseconds for voltage and current controllers as well as for the PLL synchronization unit. Pulse generators of DC-DC and VSC converters use a fast sample time of one microsecond in order to obtain an appropriate resolution of PWM waveforms.

\section{RESULTS AND ANALYSIS}

Figure 5 shows the SIMULINK model of the proposed sys-tem, where a discrete model is used for the Plant with a sample time of 50 us.

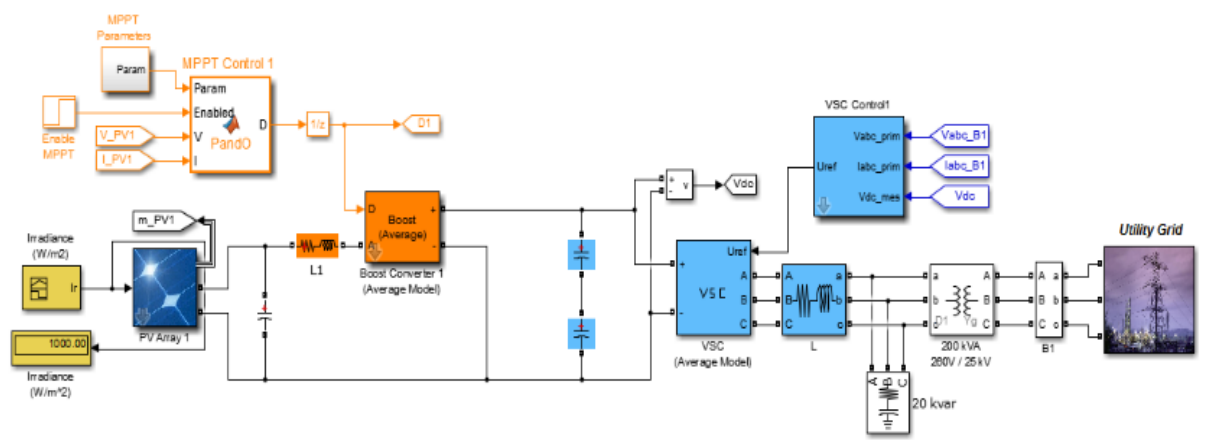

Figure 5. SIMULINK model of the grid-connected PV system. 
The DC-DC converter (orange blocks) boosts DC voltage from $273.5 \mathrm{~V}$ to $500 \mathrm{~V}$. This converter uses a MPPT system which duty cycle in order to generate the required voltage to extract maximum power. The three-level Voltage source converter regulates DC bus voltage at $500 \mathrm{~V}$ and maintains unity power factor. The control system utilizes two control loops: an external control loop which regulates DC link voltage to +/ Id and Iq grid currents (active and reactive current components). the voltage outputs of the current controller (Vd and Vq) are converted to three modulating signals Uref_abc used by the PWM three-level pulse generator. the output of the DC voltage external controller is Id current reference. Iq current reference is set to zero in order to keep unity power factor. The control system uses a sample time of 100 controllers as well as for the PLL synchronization unit. In the deta generators of Boost and VSC converters use a fast sample time of 1 appropriate resolution of PWM waveforms.

Run Simulink for 3 seconds and observe the following sequence of events on Scopes (Figure 6).

From $\mathrm{t}=0 \mathrm{~s}$ to $\mathrm{t}=0.05 \mathrm{~s}$, pulses to DC-DC and VSC converters are blocked. PV voltage corresponds to open-circuit voltage (Nser*Voc $=5 * 64.2=321 \mathrm{~V}$, see V trace on Scope Boost Figure 6). The three level bridge function as a diode rectifier and DC link capacitors are charged above $500 \mathrm{~V}$ (see Vdc_meas trace on Scope VSC)

At $\mathrm{t}=0.05 \mathrm{~s}$, Boost and VSC converters are de regulated at Vdc=500V. Duty cycle of DC-DC converter is fixed ( $D=0.5$ Figure 7$)$ and sun irradiance is fixed to $1000 \mathrm{~W} / \mathrm{m} 2$.

Stable at $\mathrm{t}=0.25 \mathrm{~s}$. Resulting Photovoltaic voltage is therefore V-PV $=\left(\begin{array}{ll}1 & 0.5\end{array}\right) * 500=250 \mathrm{~V}$ (see V trace on Scope Boost). The Photovoltaic array output power is $4.5 \mathrm{~kW}$ (see Pmean trace on Scope Boost converter).

At $\mathrm{t}=0.4 \mathrm{~s}$ the Maximum power point tracker is enabled. The MPPT regulator starts regulating Photovoltaic voltage by varying D in order to extract maximum power. Maximum power $(5 \mathrm{~kW})$ is obtained when duty cycle is $\mathrm{D}=0.453$. At $\mathrm{t}=0.6 \mathrm{~s}, \mathrm{PV}$ mean voltage $=274 \mathrm{~V}$ as expected from Photovoltaic module.

From $\mathrm{t}=0.7 \mathrm{~s}$ to $\mathrm{t}=1.2 \mathrm{~s}$, sun irradiance is ramped down from $1000 \mathrm{~W} / \mathrm{m} 2$ to $250 \mathrm{~W} / \mathrm{m} 2$. the Maximum power point tracker continues tracking maximum power. At $\mathrm{t}=1.2 \mathrm{~s}$ when irradiance has diminished to $250 \mathrm{~W} / \mathrm{m} 2$, duty cycle is $\mathrm{D}=0.485$. Corresponding $\mathrm{PV}$ voltage and power are $\mathrm{Vmean}=255 \mathrm{~V}$ and Pmean=1.2 $\mathrm{kW}$. Note that the MPPT continues tracking maximum power during this fast irradiance.

From $\mathrm{t}=1.5 \mathrm{~s}$ to $3 \mathrm{~s}$ various irradiance changes are applied in order to illustrate the nice performance of the MPPT controller.

In Figure 7 present the proper time evolution of the dc bus voltage. A typical situation in Photovoltaic systems is a variation of the solar irradiance over the Photovoltaic modules due to clouds or a sunny day: Figure 7 and figure 8 shows the time simulation of a variation in the incoming irradiance. for that, a step in the output current of the Photovoltaic generator is exerted at $0.05 \mathrm{~s}$ from a $50 \%$ up to nominal conditions with constant dc bus voltage reference: for that, the time evolution of the utility grid current at phase 1 is depicted in Figure 8 and a growing of the current can be observed.

variation an important issue to evaluate the vulnerability of the PSD+dqPLL synchronization algorithm is the survey of the degradation of the power factor in the inverter grid connection when frequency variations occur, regarding the international regulations.

The simulation of the time evolution of the detected frequency and phase, utilizing the dqPLL and the PSD + dqPLL synchronization algorithms are shown in Figure10. The rms value of the 3-phase utility grid voltage is Vrms $=500 \mathrm{~V}$ (phase-to-phase) and a step of frequency from $50 \mathrm{~Hz}$ to $60 \mathrm{~Hz}$ is exerted at 0.05 $\mathrm{s}$. The frequency detection by two algorithms is shown in Figure 10; even though the S90 filter has been elabored for a nominal frequency of $50 \mathrm{~Hz}$, a similar response to the dqPLL is achieved. admissible phase detection is attained by the PSD + dqPLL, but it must be pointed out that a small lag between the detected phases can be observed.

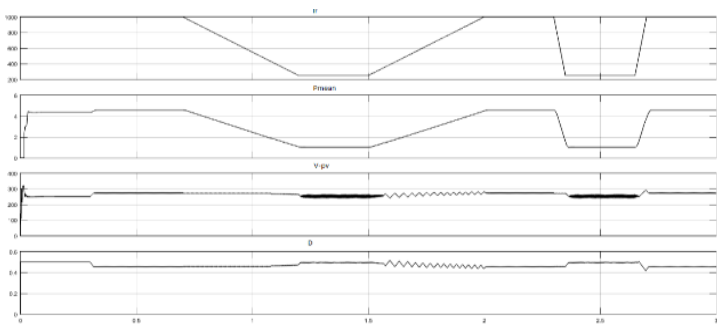

Figure 6. Waveforms of Boost Converter: Ir, Pmean, Vpv, D

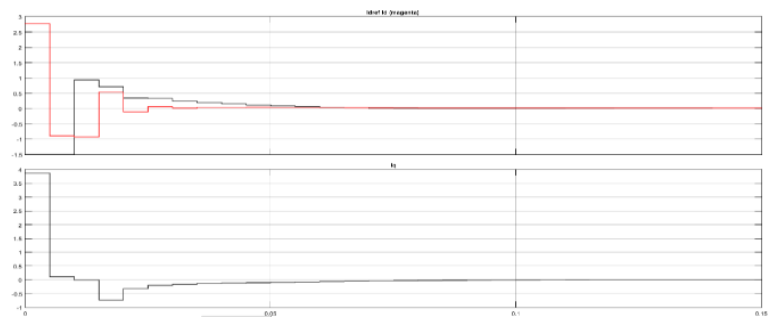

Figure 7. Response of Voltage Source Converter 


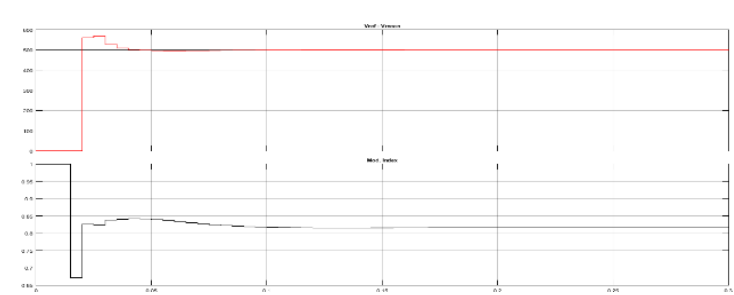

Figure 8. Response of Voltage Source Converter Waveform for Modulation Index and Inverter

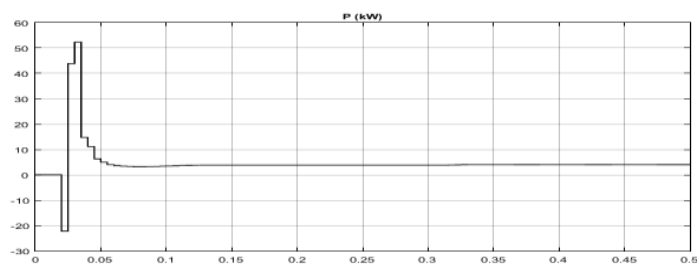

Figure 10. Synchronized Grid Power

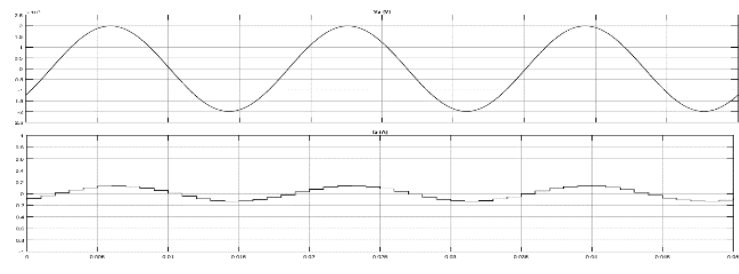

Figure 9. grid voltage and curent

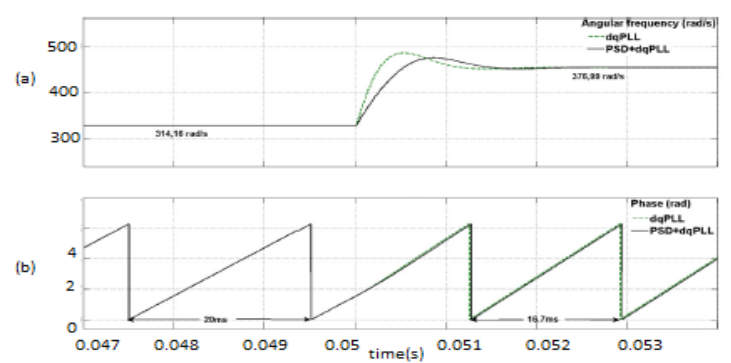

Figure 11. Time evolution of the detected frequency and phase when a step of frequency is exerted.

\section{CONCLUSION}

In the present study we performed a performance study of a Positive Sequence Detector (PSD) plus a dqPLL (PSD + dqPLL) synchronization algorithm was performed using MATLAB/SIMULINK simulations. the principle achievement has been to make an evaluation of the behavior of this synchronization algorithm by introducing several perturbations into the 3 phase utility grid. As it is known, the PSD block is built using a discrete filter which related to the nominal frequency of the utility grid, which apparently is sensitive to the variation of the nominal frequency.

The proposed Photovoltaic system can provide enhanced active power smoothing and expanded reactive power compensation. A developed dual-stage DFT PLL method was verified to be able to realize the active and reactive power separation and improve the dynamic performance of the Photovoltaic system.

\section{REFERENCES}

[1] Bennis, G., Karim, M., \& Lagrioui, A. (2015, December). Optimization of the performance of a photovoltaic system with MPPT controller. In 2015 3rd International Renewable and Sustainable Energy Conference (IRSEC) (pp. 1-6). IEEE

[2] Ghita, B., Mohammed, K., Ahmed, L., Nada, Z., Nourddine, S., \& Ayoub, E. (2016). Ortimization and modeling of a given PV system has a single phase load. Journal of Theoretical \& Applied Information Technology, 86(1).

[3] Enerdata, Global Energy Statistical Yearbook, 2013,http://yearbook.enerdata.net/energy-consumption-data.html

[4] S. Sorrell, J. Speirs, R. Bentle, A. Brandt, R. Miller, Global Oil Depletion: An Assess-ment of the Evidence for a Near-term Peak in Global Oil Production, UK EnergyResearch Centre, 2009.

[5] Recommended Practices, Requirements of Harmonic Control in ElectricalPower Systems. Standard ANSI/IEEE 519-1992, 1992.

[6] Y. Abdel-Rady, I. Mohamed, F. El-Saadany, A robust natural-frame-based inter-facing scheme for grid-connected distributed generation inverters, IEEE Trans.Energy Convers. 26 (2011) 728-736.

[7] D. Boroyevich, I. Cvetkovic, R. Burgos, D. Dong, Intergrid: a future electronicenergy network? IEEE J. Emerg. Select. Topics Power Electron. 1 (2013).

[8] F. Blaabjerg, Z. Chen, S.B. Kjaer, Power electronics as efficient interface indispersed power generation systems, IEEE Trans. Power Electron. 19 (2004)1184-1194.

[9] M. Karimi-Ghartemani, M.R. Iravani, A method for synchronization of powerelectronic converters in polluted and variable-frequency environments, IEEETrans. Power Syst. 19 (2004) 1263-1270. 
[10] A. Luna, J. Rocabert, I. Candela, P. Rodriguez, R. Teodorescu, F. Blaab-jerg, Advanced structures for grid synchronization of power converters indistributed generation applications, in: Energy Conversion Congress and Expo-sition (ECCE), 2012, pp. 2769-2776.

[11] P. Rodriguez, R. Teodorescu, I. Candela, A.V. Timbus, M. Liserre, F. Blaabjerg, Newpositive-sequence voltage detector for grid synchronization of power convert-ers under faulty grid conditions, in: Power Electronics Specialists ConferencePESC '06. 37th IEEE. 1-7, 18th June, 2006.

[12] P. Rodriguez, A. Luna, M. Ciobotaru, R. Teodorescu, F. Blaabjerg, Multires-onant frequency-locked loop for grid synchronization of power convertersunder distorted grid conditions, IEEE Trans. Ind. Electron. 58 (2011)127-138.

[13] V. Kaura, V. Blasko, Operation of a phase locked loop system under distortedutility conditions 3, Appl. Power Electron. Conf. Expos. 2 (1996) 703-708.

[14] C.L. Fortescue, Method of symmetrical co-ordinates applied to the solution ofpolyphase networks, Am. Inst. Electr. Eng. XXXVII (1918) 1027-1140.

[15] A.V. Timbus, M. Liserre, R. Teodorescu, P. Rodriguez, F. Blaabjerg, Evaluationof current controllers for distributed power generation systems, IEEE Trans.Power Electron. 24 (2009) 654-664.

[16] A.B. Rey-Boué, R. García-Valverde, F. Ruz-Vila, J.M. Torrelo-Ponce, An inte-grative approach to the design methodology for 3-phase power conditionersin photovoltaic grid-connected systems, Energy Convers. Manage. 56 (2012)80-95.

[17] A.B. Rey-Boué, R. García-Valverde, F. Ruz-Vila, J.M. Torrelo-Ponce, An inte-grative approach to the design methodology for 3-phase power conditionersin photovoltaic grid-connected systems, Energy Convers. Manage. 56 (2012)80-95.

[18] H. Akagi, E. Hirokazu Watanabe, M. Aredes, Instantaneous Power Theory andApplications to Power Conditioning, John Wiley \& Sons, New Jersey, 2007.

[19] G. Tsengenes, G. Adamidis, Investigation of the behavior of a three phase grid-connected photovoltaic system to control active and reactive power, Electr.Power Syst. Res. 81 (2011) 177-184.

[20] L. Freris, D. Infield, Features of Conventional and Renewable Generation,Renewable Energy in Power Systems, A John Wiley \& Sons, Ltd., United King-dom, 2008, pp. 21-54.

[21] G. Notton, V. Lazarov, L. Stoyanov, Optimal sizing of a grid-connected PV sys-tem for various PV module technologies and inclinations, inverter efficiencycharacteristics and locations, Renew. Energy 35 (2010) 541-554.

[22] V. Scarpa, S. Buso, G. Spiazzi, Low-complexity MPPT technique exploiting thePV module MPP locus characterization, IEEE Trans. Ind. Electron. 56 (2009)1531-1538.

[23] N. Mutoh, M. Ohno, T. Inoue, A method for MPPT control while searching forparameters corresponding to weather conditions for PV generation systems,in: IECON 2004. 30th Annual Conference of IEEE. vol. 3, 2nd November, 2004,pp. 3094-3099.

[24] K. Zhou, D. Wang, Relationship between space-vector modulation and three-phase carrier-based PWM: a comprehensive analysis [three-phase inverters],IEEE Trans. Ind. Electron. 49 (2002) 186-196.

[25] R.H. Park, Two reaction theory of synchronous machines. Generalized methodof analysis - Part I, in: Proc. Winter Convention of AIEE, 1929, pp. 716-730.

[26] A. Ferrero, G. Superti-Furga, A new approach to the definition of power com-ponents in three-phase systems under nonsinusoidal conditions, IEEE Trans.Instrum. Measure. 40 (1991) 568-577.

[27] R. Ekstrom, M. Leijon, Lower order grid current harmonics for a voltage-sourceinverter connected to a distorted grid, Electr. Power Syst. Res. 106 (2014)226-231.

[28] [27] Standard for Interconnecting Distributed Resources with Electric Power Sys-tems, 2003.

[29] J.C. Hernández, J. Ortega, De la Cruz, D. Vera, Guidelines for the technical assess-ment of harmonic, flicker and unbalance emission limits for PV-distributedgeneration, Electr. Power Syst. Res. 81 (2011) 1247-1257.

[30] E.J. Bueno, F. Espinosa, F.J. Rodriguez, J. Urefi, S. Cobrece, Current control ofvoltage source converters connected to the grid through an LCL-filter, in: PowerElectronics Specialists Conference, 2004 IEEE 35th Annual, vol. 1, 2004, pp.68-73.

[31] D. Hamza, Q. Mei, P.K. Jain, Implementation of an EMI active filter in grid-tiedPV micro-inverter controller and stability verification, in: IECON, 25th October,2012, pp. 477-482.

[32] S. Wang, C. Xu, H. Qin, Design theory and implementation of planar EMI fil-ter based on annular integrated inductor-capacitor unit, Electromagn. Compat.(APEMC) (2013) 129-132.

[33] C. Po-Shen, L. Yen-Shin, Effective EMI filter design method for three-phaseinverter based upon software noise separation, IEEE Trans. Power Electron. 25(2010) 2797-2806.

[34] N.S. D' Souza, L.A.C Lopes, X. Liu, Comparative study of variable size perturbation and observation maximum power point trackers for PV systems, Electr.Power Syst. Res 80(2010) 296- 